\title{
Preschool vision screening: outcome of children referred to the hospital eye service
}

Department of Ophthalmology, Addenbrooke's Hospital, Cambridge D K Newman $\mathrm{J}$ Keast-Butler A T Moore

\section{Department of Orthoptics, Addenbrooke's Hospital, Cambridge A Hitchcock H McCarthy \\ Correspondence to: Douglas K Newman Department of Ophthalmology, Clinic 3 (Box 41), Addenbrooke's Hospital, Hills Road,} Cambridge CB2 2QQ.

\author{
Douglas K Newman, Anne Hitchcock, Helen McCarthy, John Keast-Butler, \\ Anthony T Moore
}

or in combination. Amblyopia is amenable to treatment, but only during the sensitive period. Detection of amblyopia at a young age is advocated since the visual outcome is considered to be better the earlier treatment is commenced in the sensitive period.

For most amblyopic children early detection depends on vision screening. Only those children with a cosmetically noticeable squint, or other obvious visual problem, will present at a young age without screening. ${ }^{2-5}$ Until recently a child's vision was first assessed upon school entry at 5 to 6 years of age. However, treatment of amblyopia detected at this age is often unsatisfactory. ${ }^{6}$ Preschool vision screening has therefore been introduced with the aim of detecting amblyopia at a younger age. The age of $3 \frac{1}{2}$ years has commonly been adopted for screening since this is the youngest age at which monocular visual acuity can be reliably assessed in the majority of children. ${ }^{7}$

Several studies have examined the efficacy of screening preschool children for amblyopia. Most screening programmes incorporate an assessment of both vision and ocular alignment, though considerable variation exists in the precise tests employed. ${ }^{8}$ Current methods of screening have been shown to perform well when conducted by appropriately trained personnel. Thus, orthoptist based screening programmes have high sensitivity and specificity. ${ }^{9}$ Screening by other personnel, however, is generally associated with unacceptably high false positive and false negative rates. ${ }^{10-12}$

In contrast, little is known about the results of treating amblyopic children detected by preschool vision screening. The few studies reported have found both good ${ }^{1213}$ and poor ${ }^{14}$ results. It has been suggested that detection of amblyopia at $3 \frac{1}{2}$ years of age may be too late to allow effective treatment. Preschool vision screening also leads to the detection of children with other visual defects, in particular strabismus and refractive error (without associated amblyopia). Whether these children benefit from early detection is also uncertain. We have therefore performed a retrospective study to determine the visual outcome of all children referred to the hospital eye service (HES) from an orthoptist based preschool vision screening programme.

\section{Subjects and methods}

A retrospective study was performed of children referred to the HES from the Cambridge preschool vision screening programme during 
Table 1 Reasons for referral from screening

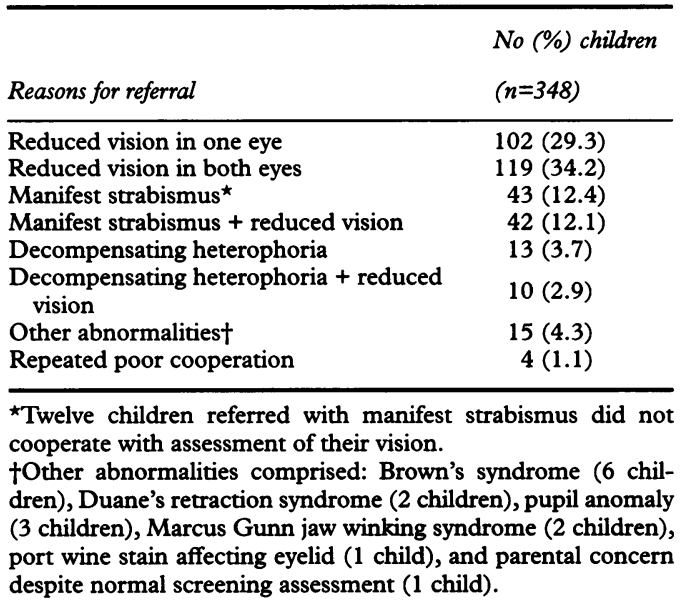

the 2 year period October 1984 to September 1986 inclusive. This cohort was chosen so that the children would have completed all treatment for amblyopia and/or strabismus at the time of the study, enabling their visual outcome to be assessed. The medical records of each child were reviewed to determine the following: reason for referral from screening, HES findings, treatment received by children with confirmed visual defects, and final visual outcome.

\section{ORGANISATION OF THE VISION SCREENING} PROGRAMME

The Cambridge preschool vision screening programme covered the Cambridge Health Authority area, with a population of 269000 (estimated resident population for 1985 based on the 1981 census, Office of Population Censuses and Surveys). It also covered the adjacent Huntingdon Health Authority area for the first 6 months of the study period, with a population of 126000 (estimated resident population for 1985 based on the 1981 census, Office of Population Censuses and Surveys). Children aged $3 \frac{1}{2}$ years were identified by the Community Child Health Service from its register of children resident in the area. An invitation to attend screening was sent direct to the child's parents or guardian. Any child who failed to attend screening at the first invitation was sent one further invitation. Screening was conducted by a community orthoptist at a venue close to the child's home, either in a local health centre or in a specially designed mobile unit.

VISION SCREENING ASSESSMENT

After taking a brief history, the child was examined as follows: (1) monocular visual acu-

Table 2 Hospital eye service (HES) findings for children referred from screening

\begin{tabular}{ll}
\hline & No (\%) children \\
HES findings & $(n=304)$ \\
\hline Refractive error & $100(32.9)$ \\
Amblyopia & $91(29.9)$ \\
Straight eyed amblyopia & $48(15.8)$ \\
Strabismic amblyopia & $43(14.1)$ \\
False positive referral & $61(20.1)$ \\
Strabismus & $40(13.2)$ \\
Other ocular disorders & $12(3.9)$ \\
\hline
\end{tabular}

Table 3 Visual acuity achieved in amblyopic eye

\begin{tabular}{lll}
\hline $\begin{array}{l}\text { Visual acuity } \\
\text { linear optotype } \\
\text { test) }\end{array}$ & $\begin{array}{l}\text { No (\%) children with } \\
\text { straight eyed amblyopia } \\
(n=47)\end{array}$ & $\begin{array}{l}\text { No (\%) children } \\
\text { with strabismic } \\
\text { amblyopia }(n=42)\end{array}$ \\
\hline $6 / 6$ or better & $28(59.6)$ & $13(31.0)$ \\
$6 / 9$ & $13(27.7)$ & $14(33.3)$ \\
$6 / 12$ & $4(8.5)$ & $9(21.4)$ \\
$6 / 18$ & - & $3(7.1)$ \\
$6 / 24$ & $2(4.3)$ & $2(4.8)$ \\
$6 / 36$ & - & $1(2.4)$ \\
\hline
\end{tabular}

The last known visual acuity was assessed with a single optotype test for two children with straight eyed amblyopia (acuity $6 / 6$ and $6 / 12$ respectively) and one child with strabismic amblyopia (acuity 6/24).

ity (single optotype Sheridan-Gardiner test at 6 metres), (2) cover test at near and distance fixation, (3) ocular movements and convergence, (4) binocular single vision $\left(20^{\Delta}\right.$ base out prism test), and (5) stereopsis (TNO stereotest screening plate). The screening assessment took on average 7 minutes to perform.

The criteria for referral to the HES for further assessment were: (1) visual acuity less than $6 / 6$ in either eye, (2) manifest strabismus, (3) decompensating heterophoria, (4) abnormality of ocular movements, (5) abnormal response to $20^{\Delta}$ base out prism test, (6) negative response to stereotest, or (7) any other ocular abnormality. The child's general practitioner was informed of this referral. In the presence of equivocal findings, a child was recalled for another screening assessment by the community orthoptist.

\section{CHILDREN REFERRED TO THE HOSPITAL EYE} SERVICE

At the first visit to the HES, cycloplegic refraction was performed by an ophthalmologist and spectacles prescribed for significant refractive errors. The ocular media and fundus were also examined in all cases. A full orthoptic examination was performed at a subsequent visit, 1 to 2 months later. Visual acuity was measured, with spectacle correction if prescribed, using a linear optotype test (Snellen or SheridanGardiner) whenever possible.

Children found to have amblyopia and/or strabismus were treated along conventional lines. Amblyopia was treated with total occlusion, either part time or full time depending on the clinical situation. Children with reduced vision due only to refractive error were discharged to an optometrist once amblyopia had been confidently excluded.

\section{STUDY DEFINITIONS}

For the purposes of this study, amblyopia was defined as present if a child was prescribed occlusion therapy. Children with amblyopia were subdivided into two groups: straight eyed amblyopes and strabismic amblyopes. Strabismus was defined as the presence of a manifest deviation on cover testing. Children with an organic lesion contributing to their defective vision were considered separately. A child was considered to have a refractive error if spectacles were prescribed by the examining ophthalmologist. Anisometropia was defined as a difference in refraction between the two eyes of $1.00 \mathrm{D}$ or more in any meridian. The visual 
outcome at discharge from the HES (or last attendance if defaulted follow up) was determined for all children with amblyopia, regardless of compliance with treatment.

\section{Results}

Preschool vision screening was offered to 8566 children. The attendance rate was $79.3 \%$ (6794 children). In all, 348 children ( $5.1 \%$ of those screened) were referred to the HES. The mean age at screening for these children was 3.7 years (SD 0.3 years). Children were mostly referred from screening because of reduced vision or strabismus (Table 1). No child required referral solely because of failing the $20^{\Delta}$ base out prism test or the TNO screening stereotest.

The HES findings are known for 304 children (Table 2). None had previously been identified as having a visual defect. No diagnosis is known for 44 children; 15 failed to attend the HES following referral, 16 attended the HES insufficiently to allow reliable evaluation (10 defaulted follow up and six were transferred to another HES), and the medical records of 13 were unavailable for review.

The positive predictive value of screening for detecting a visual defect was $79.9 \%(243 / 304)$. The 61 children found to be false positive referrals had failed screening for the following reasons: reduced vision in one eye $(20)$ or both eyes (23), manifest strabismus (5), decompensating heterophoria alone (8) or with reduced vision (3), repeated poor cooperation (1), and parental concern despite normal screening assessment (1). Children with a well compensated heterophoria were regarded as false positive referrals. Many of the false positive referrals had required a period of review at the HES in order to exclude defective vision and/or strabismus with certainty. Their mean age at discharge was 5.8 years (SD 1.2 years).

\section{CHILDREN WITH AMBLYOPIA}

Ninety one children had amblyopia; 48 were straight eyed and 43 were strabismic. The straight eyed amblyopes comprised 41 children with hypermetropic anisometropia, four children with microtropia with identity, and three children with unknown aetiology. The strabismic amblyopes included 19 children with combined strabismus and hypermetropic anisometropia. There were no cases of bilateral ametropic amblyopia.

The visual outcome was known for 89 children. Their mean age at discharge was 7.7 years (SD 1.4 years). The remaining two children had been transferred to another HES before completion of occlusion therapy. Table 3 gives the visual acuity achieved in the amblyopic eye. An acuity of $6 / 9$ or better was achieved by $87.2 \%(41 / 47)$ straight eyed amblyopes and $64.3 \%(27 / 42)$ strabismic amblyopes $\left(\chi^{2}=5.27, \mathrm{p}=0.02\right)$. In addition, good stereopsis was achieved by the majority of straight eyed amblyopes; $70.5 \%$ (31/44) achieved 60 seconds of arc or better and a further $18.2 \%(8 / 44)$ achieved at least 240 seconds of arc. Stereopsis had not been
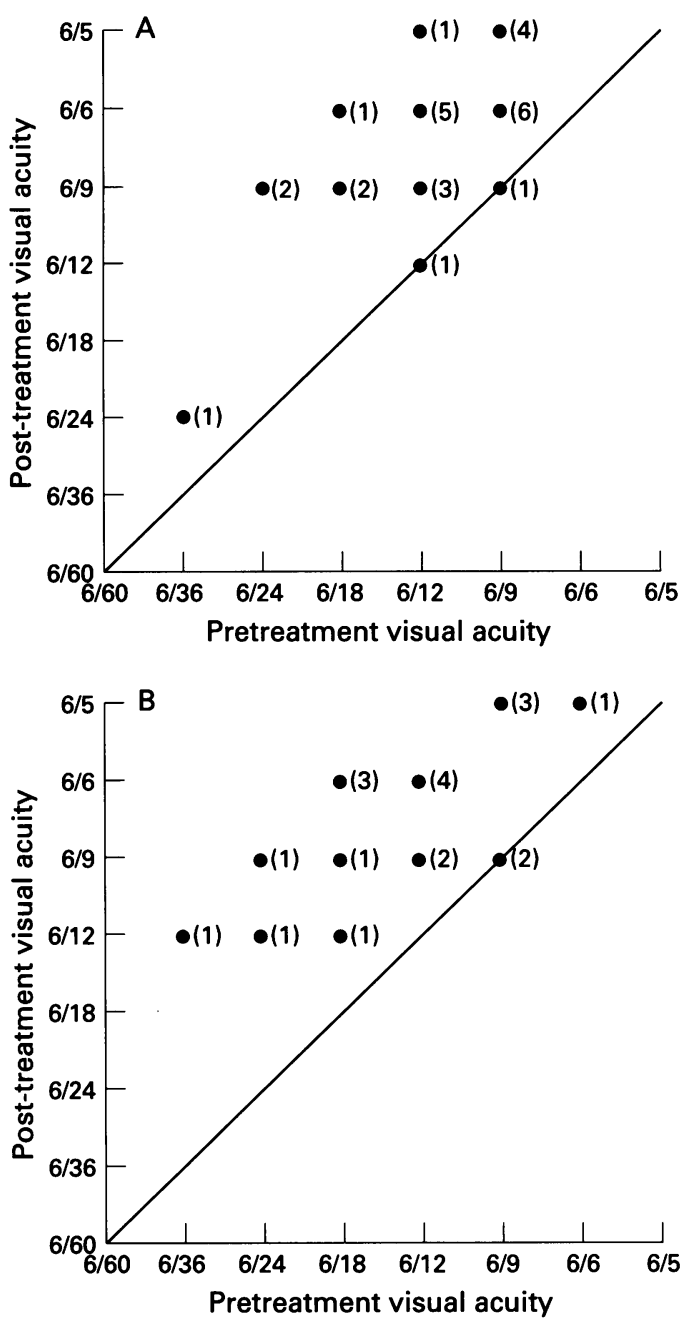

Figure 1 Result of occlusion therapy for children with a linear optotype pretreatment visual acuity. (A) Straight eyed amblyopes $(n=27)$ and $(B)$ strabismic amblyopes $(n=20)$. Numbers of children are given in parentheses. All post-treatment visual acuities were assessed with a linear optotype test.

assessed for three children after completion of occlusion therapy.

The efficacy of amblyopia treatment could only be determined for 47 children whose pretreatment corrected acuity had been measured with a linear optotype test. Improvement by two Snellen lines or more was achieved by $55.6 \%(15 / 27)$ straight eyed amblyopes and $70.0 \%(14 / 20)$ strabismic amblyopes (Fig 1). It was not possible to quantify the visual improvement achieved by the remaining children because their pretreatment corrected acuity had only been measured with a single optotype test (Fig 2). Single and linear optotype acuities are not directly comparable, particularly in amblyopic individuals. ${ }^{15}$

\section{CHIIDREN WITH REFRACTIVE ERROR}

One hundred children had a refractive error without associated amblyopia or strabismus. Spectacles were initially prescribed for these children to enable assessment of their corrected acuity and thereby exclude the presence of amblyopia. With spectacle correction, they all achieved an acuity of $6 / 6$ or better in each eye (except two children with a best recorded acuity of $6 / 9$ in each eye). Many of these children were reviewed at the HES for a period 

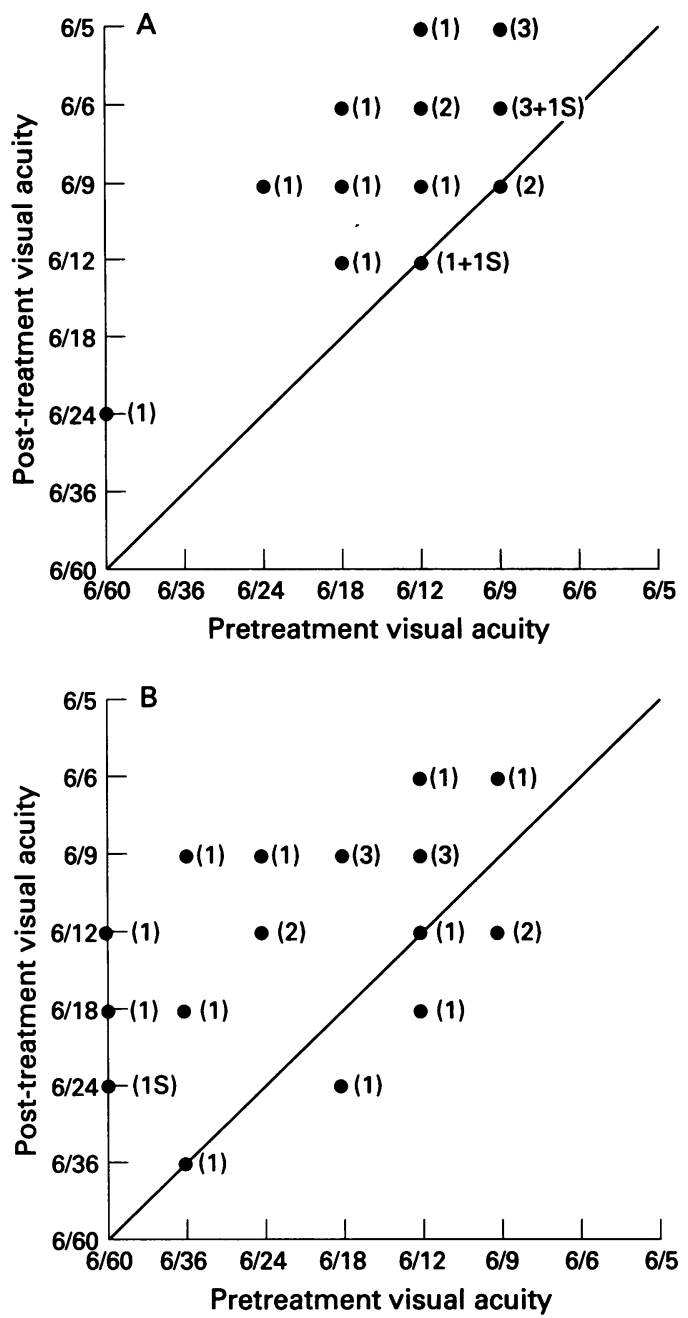

Figure 2 Result of occlusion therapy for children with a single optotype pretreatment visual acuity. (A) Straight eyed amblyopes $(n=20)$ and $(B)$ strabismic amblyopes $(n=22)$. Numbers of children are given in parentheses. The post-treatment visual acuities were assessed with a linear optotype test, except for three children in whom a single optotype test was used ('S').

to exclude amblyopia and/or strabismus with certainty. Their mean age at discharge was 6.6 years (SD 1.3 years).

Table 4 gives the refractive errors found for this group of children. Potentially amblyogenic refractive errors include hypermetropic anisometropia (1.00 D or more) and high bilateral hypermetropia $\left(+4.00 \mathrm{D}\right.$ or more). ${ }^{16}$ Such refractive errors were present in 25 children, some of whom may have had refractive amblyopia which was adequately treated by spectacle correction alone. Table 5 gives the unaided visual acuity in each eye for this group of children. In most cases, the unaided visual acuity was not retested after the screening assessment and is therefore only available as a single optotype visual acuity. Many of these children had only a relatively minor reduction of vision due to uncorrected refractive errors. At discharge from the HES, 85 children were still wearing spectacles.

CHILDREN WITH STRABISMUS

Forty children had strabismus without amblyopia. Concomitant strabismus was present in 34 children; 14 were esotropic and 20 were exotropic. Early detection and treatment as a
Table 4 Children with refractive error: spectacle correction prescribed

\begin{tabular}{lll}
\hline $\begin{array}{l}\text { Spherical equivalent in } \\
\text { more ametropic eye }(D)\end{array}$ & $\begin{array}{l}\text { Hypermetropia } \\
(n=66)\end{array}$ & $\begin{array}{c}\text { Myopia } \\
(n=34)\end{array}$ \\
\hline$<2.00$ & $36(9)^{\star}$ & 24 \\
$2.00-3.99$ & $21(7)^{\star}$ & 8 \\
$4.00-5.99$ & $8(4)^{\star}$ & 2 \\
$6.00-7.99$ & 1 & - \\
\hline
\end{tabular}

\begin{tabular}{ll}
\hline Hypermetropic anisometropia $(D)$ & No of children $(n=20)$ \\
\hline $1.00-1.75$ & 15 \\
$2.00-2.75$ & 4 \\
$3.00-3.75$ & 1 \\
\hline \hline Cylinder in eye with greater & No of children $(n=100)$ \\
astigmatism (D) & 32 \\
\hline$<1.00$ & 65 \\
$1.00-2.75$ & 3 \\
$3.00-4.75$ &
\end{tabular}

Spherical equivalent was calculated as the sum of the sphere and half of the cylinder.

Anisometropia was calculated as the maximum difference in refraction between the two eyes in any meridian.

${ }^{\star}$ Children with hypermetropic anisometropia.

Table 5 Children with refractive error: unaided visual acuity in each eye (single optotype test)

\begin{tabular}{lcrrrl}
\hline \multirow{2}{*}{$\begin{array}{l}\text { Unaided } \\
\text { visual acuity } \\
\text { in worse eye }\end{array}$} & \multicolumn{5}{c}{ Unaided visual acuity in better eye } \\
\cline { 2 - 6 } & $6 / 6$ & $6 / 9$ & $6 / 12$ & $6 / 18$ & $6 / 24$ \\
\hline $6 / 6$ & 1 & & & & \\
$6 / 9$ & 10 & 18 & & & \\
$6 / 12$ & 17 & 10 & 29 & & \\
$6 / 18$ & & 2 & 3 & 5 & \\
$6 / 24$ & & & 1 & 1 & 1 \\
\hline
\end{tabular}

An unaided visual acuity was not available for two children, both of whom were prescribed spectacles because of a potentially amblyogenic refractive error.

result of screening may have prevented some of these children developing amblyopia. Treatment comprised spectacles for 11 children, strabismus surgery for 10 children, and both for four children. Incomitant strabismus was present in six children-five had Brown's syndrome and one had Duane's retraction syndrome. They were reviewed at the HES, but none required any treatment.

CHILDREN WITH OTHER OCULAR DISORDERS

Seven children had an organic lesion contributing to their reduced vision: megalocornea, mild lenticular opacity, macular scar (probable Purtscher's retinopathy), hereditary maculopathy, diffuse choroidal haemangioma (SturgeWeber syndrome), optic nerve hypoplasia, and resolved papilloedema (following treated hydrocephalus). Five of these children gained visual improvement following spectacle prescription and/or occlusion therapy for associated amblyopia. A further five children had miscellaneous ocular disorders with normal vision-Marcus Gunn jaw winking syndrome (two children), congenital anisocoria, persistent pupillary fibres, and minor anterior segment dysgenesis.

\section{Discussion}

Preschool vision screening conducted by orthoptists is effective in detecting children with visual defects. ${ }^{9}$ The efficacy of orthoptist based programmes, compared with screening by 
other personnel, reflects the expertise required to assess vision and ocular alignment accurately in young children. ${ }^{10-12}$ Even in experienced hands, however, some 31/2-year-old children will not cooperate with the screening assessment. ${ }^{7}$ The facility to recall children with equivocal findings is therefore important to reduce false positive referrals. ${ }^{17}$ Our screening programme, which incorporated a recall facility, achieved a positive predictive value of $79.9 \%$. Apparently reduced vision at screening accounted for the majority of false positive referrals. Comparable studies have reported positive predictive values ranging from $74 \%$ to $94 \% .^{9111718}$

Debate continues regarding the best screening tests for preschool children. A single optotype test of visual acuity (Sheridan-Gardiner) was employed in this study because it can be reliably used in the majority of $3 \frac{1}{1} 2$-year-old children. ${ }^{19}$ A low threshold for referral (acuity less than 6/6) was required because single optotype tests lack visual crowding and may underestimate amblyopia. ${ }^{15}$ 'Crowded' optotype tests suitable for preschool children are available, but have only recently been evaluated for screening. ${ }^{20}$ Various tests of binocularity are also employed for preschool vision screening. The $20^{\Delta}$ base out prism test and a TNO stereotest screening plate (1980 seconds of arc) were used in this study. No child failed screening solely on the result of these tests, suggesting they could safely be omitted. Similar findings have been reported in another study. ${ }^{18}$ However, stereopsis testing at a higher threshold has been suggested as a useful single screening test. $^{21-24}$

Preschool vision screening by orthoptists is generally conducted separately from other child health surveillance programmes. Uptake is encouraged by a community based approach to screening using local venues. The attendance rate for our screening programme was $79.3 \%$. Sending a second invitation to nonattenders was found to be beneficial: approximately $40 \%$ of these children subsequently attended screening. Most other studies have reported similar attendance rates, varying from $72 \%$ to $75 \% .^{9^{1012-14}}$ However, lower attendance rates have been reported for inner city populations $\left(57 \%^{18}\right.$ and $\left.60 \%{ }^{11}\right)$.

AMBLYOPIC CHILDREN DETECTED BY PRESCHOOL VISION SCREENING

The principal aim of preschool vision screening is to detect children with unsuspected amblyopia at an age when treatment is effective. The results of this study indicate that most amblyopic children detected by screening at $3 \frac{1}{2}$ years of age achieve a good visual outcome with treatment. An acuity of $6 / 9$ or better in the amblyopic eye was achieved by $87.2 \%$ of straight eyed amblyopes and $64.3 \%$ of strabismic amblyopes. Residual amblyopia of $6 / 24$ or worse occurred in only $5.6 \%$ of amblyopic children. These results include every child regardless of compliance with treatment and therefore reflect 'real' clinical practice. A better outcome in straight eyed compared with strabismic amblyopia has been found in other studies. ${ }^{2526}$

The efficacy of amblyopia treatment, as assessed by improvement in the corrected acuity of the amblyopic eye, could only be determined for 47 of the 91 amblyopic children. For these children, improvement by two Snellen lines or more was achieved by $55.6 \%$ of straight eyed amblyopes and $70.0 \%$ of strabismic amblyopes. The remaining children were excluded from this analysis because their pretreatment corrected acuity had not been measured with a linear optotype test. Many of these children, however, had moderate to severe amblyopia (as assessed by single optotype acuities) but ultimately achieved a good visual outcome. It is therefore likely that the above figures underestimate the overall efficacy of our amblyopia treatment.

For the purposes of this study, all children prescribed occlusion therapy were considered to have amblyopia. It was not possible to apply a strict definition of amblyopia based on a precise deficit in corrected visual acuity because the acuity of many children had been measured with only a single optotype test before commencing occlusion therapy. This is an important limitation of our study since it may have resulted in some children being incorrectly classified as amblyopes due to a low threshold for prescribing occlusion therapy. The indication for prescribing occlusion therapy was, however, in all cases the presence of a definite unilateral deficit in corrected visual acuity (whether measured by a single or linear optotype test).

Only a few studies have previously examined the results of treating amblyopic children detected by preschool vision screening. Beardsell reported encouraging results in her small cohort which included referrals from both primary and secondary screening. ${ }^{13}$ Bolger et al also found that the visual acuity of the amblyopic eye improved with treatment for most children, but did not specify the final visual acuity attained. ${ }^{12}$ In contrast, Ingram et al reported a poor response to amblyopia treatment in their small cohort ${ }^{14}$ suggesting that $3 \frac{1}{2}$ years of age might be too late for effective treatment. Their poor results may perhaps be attributable instead to other factors such as the treatment regimen or poor compliance. Finally, there is some evidence from epidemiological studies that the prevalence of amblyopia is reduced by preschool vision screening. ${ }^{27-29}$

We conclude that amblyopia detected by preschool vision screening can be effectively treated in the majority of cases. However, a controlled study has yet to be performed to determine whether preschool screening at $3 \frac{1}{2}$ years of age results in a better outcome than screening at school entry when aged 5 to 6 years. Such a study should be possible since some health districts in the UK do not currently conduct preschool vision screening. ${ }^{8}$ A controlled study is particularly important in view of some recent reports that the visual outcome in amblyopia may not necessarily depend on age at presentation. ${ }^{263031}$ Furthermore, any improvement in visual outcome must be shown to justify 
the cost and greater logistic difficulties associated with screening before school entry.

\section{CORRECTION OF REFRACTIVE ERRORS IN}

PRESCHOOL CHILDREN

Preschool vision screening using tests of visual acuity inevitably results in the detection of children without amblyopia who have reduced vision due to uncorrected refractive errors. Such children comprised the single largest group referred from screening in this study and similar findings have been reported elsewhere. ${ }^{1013171832}$ Referral of these children to the HES and their subsequent treatment increase the overall cost of a preschool vision screening programme. However, the extent to which these children benefit from early correction of their refractive error is uncertain.

Spectacles were initially prescribed for this group of children to allow assessment of corrected acuity and thereby exclude the presence of amblyopia. There are two indications for continued spectacle prescription. Firstly, potentially amblyogenic refractive errors are corrected during the period of visual maturation to ensure normal binocular visual development. The precise threshold at which refractive errors may induce amblyopia has not, however, been clearly defined. ${ }^{16}$ Secondly, spectacles may be prescribed to improve a child's vision. In this study, only a minority of children had substantially reduced vision due to uncorrected refractive errors. Since a child's general development is not adversely affected by untreated minor defects of visual acuity, ${ }^{334}$ a number of children may have been prescribed spectacles without significant benefit. Further research is therefore required on both counts to clarify the value of detecting this group of children and correcting their refractive errors.

\section{CONCLUSION}

Well defined criteria have been established for conditions which merit screening. ${ }^{35}$ These have yet to be fully satisfied in the case of screening preschool children for amblyopia. Previous studies have shown that screening by orthoptists is effective in detecting children with amblyopia. The results of this study indicate that most amblyopic children detected by such screening programmes achieve a good visual outcome with treatment. A controlled study is now needed to determine whether earlier detection through preschool screening results in a better outcome than screening at school entry. The cost effectiveness of preschool vision screening also needs to be assessed. Any such analysis must take into account the significant number of children detected by screening without amblyopia who have reduced vision due to uncorrected refractive error.

The authors are grateful to the consultant ophthalmologists and orthoptists at Addenbrooke's Hospital (Cambridge), Hinchingbrooke Hospital (Huntingdon), Newmarket General Hospital (Newmarket), and The Princess of Wales Royal Air Force Hospital (Ely) for permission to review their patients in this study. We also wish to thank Dr Darrel Francis for his help in setting up a computerised database.
1 von Noorden GK. Binocular vision and ocular motility: theory and management of strabismus. 4th ed. St Louis: CV Mosby, 1990.

2 Oliver M, Nawratzki I. Screening of pre-school children for ocular anomalies. II. Amblyopia-prevalence and therapeutic results at different ages. $\mathrm{Br} \mathcal{F}$ Ophthalmol 1971;55: 467-71.

3 Ingram RM. The problem of screening children for visual defects. Br $\mathcal{F}$ Ophthalmol 1977;61:4-7.

4 Shaw DE, Fielder AR, Minshull C, Rosenthal AR. Amblyopia-factors influencing age of presentation. Lancet 1988;ii:207-9.

5 Woodruff G, Hiscox F, Thompson JR, Smith LK. The presentation of children with amblyopia. Eye 1994;8:623-6.

6 Ingram RM. Review of children referred from the school vision screening programme in Kettering during 1976-8. $B M \mathcal{F}$ 1989;298:935-6.

7 Egan DF, Brown R. Vision testing of young children in the age range 18 months to $4 \frac{1}{2}$ years. Child Care Health Dev age range $18 \mathrm{~m}$

8 Stewart-Brown SL, Haslum MN, Howlett B. Preschool vision screening: a service in need of rationalisation. Arch Dis Child 1988;63:356-9.

9 Wormald RPL. Preschool vision screening in Cornwall: performance indicators of community orthoptists. Arch Dis Child 1991;66:917-20.

10 Edwards RS, Whitelaw AJ, Abbott AG. Orthoptists as pre-school screeners: a 2-year study. Br Orthopt $\mathcal{f}$ 1989;46: $14-9$.

11 Jarvis SN, Tamhne RC, Thompson L, Francis PM, Anderson J, Colver AF. Preschool vision screening. Arch Dis Child son J, Colver AF.
1990;65:288-94.

12 Bolger PG, Stewart-Brown SL, Newcombe E, Starbuck A. Vision screening in preschool children: comparison of orthoptists and clinical medical officers as primary screeners. $B M \mathcal{F}$ 1991;303:1291-4.

13 Beardsell R. Orthoptic visual screening at $3 \frac{1}{2}$ years by Huntingdon Health Authority. Br Orthopt f 1989;46:7-13.

14 Ingram RM, Holland WW, Walker C, Wilson JM, Arnold $\mathrm{PE}$, Dally S. Screening for visual defects in preschool children. Br $¥$ Ophthalmol 1986;70:16-21.

15 Hilton AF, Stanley JC. Pitfalls in testing children's vision by the Sheridan Gardiner single optotype method. $\mathrm{Br} f$ Ophthalmol 1972;56:135-9.

16 Moore AT. Refraction in childhood. Trans Ophthalmol Soc UK 1985;104:648-52.

17 Köhler L, Stigmar G. Vision screening of four-year-old children. Acta Paediatr Scand 1973;62:17-27.

18 Williamson TH, Andrews R, Dutton GN, Murray G, Graham N. Assessment of an inner city visual screening programme for preschool children. $\mathrm{Br} \quad \mathcal{f}$ Ophthalmol 1995;79:1068-73.

19 Simons $\mathrm{K}$. Visual acuity norms in young children. Surv Ophthalmol 1983;28:84-92.

20 Salt AT, Sonksen PM, Wade A, Jayatunga R. The maturation of linear acuity and compliance with the Sonksen-Silver acuity system in young children. Dev Med Child Neurol 1995;37:505-14.

21 Reinecke RD, Simons K. A new stereoscopic test for amblyopia screening. Am $\mathcal{f}$ Ophthalmol 1974;78:714-21.

22 Walraven J. Amblyopia screening with random-dot stereograms. Am ₹ Ophthalmol 1975;80:893-900.

23 Mølgaard I-L, Biering-Sørensen K, Michelsen N, Elmer J, Rydberg A. Amblyopia screening in kindergartens with Rydberg A. Amblyopia screening in kindergarte

24 Hammond RS, Schmidt PP. A random dot E stereogram for the vision screening of children. Arch Ophthalmol 1986;104: 54-60.

25 Hiscox F, Strong N, Thompson JR, Minshull C, Woodruff G. Occlusion for amblyopia: a comprehensive survey of outcome. Eye 1992;6:300-4.

26 Woodruff G, Hiscox F, Thompson JR, Smith LK. Factors affecting the outcome of children treated for amblyopia. Eye 1994;8:627-31.

27 Köhler L, Stigmar G. Visual disorders in 7-year-old children with and without previous vision screening. Acta Paediatr Scand 1978;67:373-7.

28 Jensen H, Goldschmidt E. Visual acuity in Danish school children. Acta Ophthalmol 1986;64:187-91.

29 Vinding T, Gregersen E, Jensen A, Rindziunski E. Prevalence of amblyopia in old people without previous screening and treatment. Acta Ophthalmol 1991;69:796-8.

30 Hardman-Lea SJ, Loades J, Rubinstein MP. The sensitive period for anisometropic amblyopia. Eye 1989;3:783-90.

31 Lithander J, Sjöstrand J. Anisometropic and strabismic amblyopia in the age group 2 years and above: a prospective amblyopia in the age group 2 years and above: a prospective
study of the results of treatment. Br $\mathcal{O}$ Ophthalmol 1991;75: study of th.

32 Fathy VC, Elton PJ. Orthoptic screening for three- and four-year-olds. Public Health 1993;107:19-23.

33 Stewart-Brown S, Haslum MN, Butler N. Educationa attainment of 10-year-old children with treated and untreated visual defects. Dev Med Child Neurol 1985;27: 504-13.

34 Stewart-Brown SL, Brewer R. The significance of minor defects of visual acuity in school children: implications for screening and treatment. Trans Ophthalmol Soc UK 1986;105:287-95.

35 Wilson JMG, Jungner G. Principles and practice of screening for disease. Geneva: World Health Organisation, Public Health Papers No 34, 1968.
Hearease. 